ARTÍCULO DE INVESTIGACIÓN

\title{
Anatomía comparada de leño y corteza de Geoffroea striata y Geoffroea decorticans
}

\author{
Ana María Giménez
}

\begin{abstract}
RESUMEN
En Argentina vegetan dos especies arbóreas del género Geoffroea: Geoffroea striata Morong (manduvi-rá) y Geoffroea decorticans Burkart (chañar). Ambas tienen importancia florística, son usadas localmente pero sus maderas no tienen valor comercial. En este trabajo se describen la madera y la corteza de Geoffroea striata y para contribuir a su conocimiento, se realiza anatomía comparada con Geoffroea decorticans. El material fue colectado en el bosque natural de la Localidad Isla del Cerrito en Chaco (distrito chaqueño oriental) y de Los Flores, en Santiago del Estero (distrito chaqueño occidental). Se seleccionaron al azar cinco individuos de cada especie, obteniéndose una rodaja de $5 \mathrm{~cm}$ del tronco a 1,3 $\mathrm{m}$ del suelo. Para las descripciones del leño o madera se usó la terminología establecida por el Comité de Nomenclatura de IAWA. Las descripciones de corteza se realizaron según los criterios de distribución de patrones de tejidos y la terminología de Roth. Se concluyó que Geoffroea striata es una especie de gran afinidad anatómica con Geoffroea decorticans, pudiendo tener un uso alternativo su madera. En el leño las variables con diferencias significativas son: Iongitud de vasos, número de vasos $/ \mathrm{mm}^{2}$; diámetro externo, interno y espesor de pared de fibras, así como la longitud de radios. En la corteza, las principales diferencias residen en el aspecto externo. Ambas especies presentan caracteres evolutivos en corteza y madera.
\end{abstract}

PALABRAS CLAVE:

Anatomía, corteza,Geoffroea, leño.

\begin{abstract}
Two are the arboreal species of the genus Geoffroea that vegetate in Argentina: Geoffroea striata Morong (manduvi-rá) and Geoffroea decorticans Burkart (chañar). Both have floristic importance, are used locally but their woods have no commercial value. The objectives of this work are: to describe the wood and bark anatomy of Geoffroea striata and contribute to their knowledge, to compare it anatomically with Geoffroea decorticans. The material was collected from natural forests of Isla del Cerrito Locality in Chaco (Chaco eastern district) and Los Flores, in Santiago del Estero (Chaco western district). Five trees of each species were selected at random, obtaining a disc of $5 \mathrm{~cm}$ from the trunk at 1,3 m. In wood descriptions the IAWA Nomenclature was used. Bark descriptions were made according to standards of tissues distribution and the terminology of Roth. It may be Concluded that Geoffroea striata is a tree of great anatomical affinity with Geoffroea decorticans, being susceptible to have an alternative use of its wood. The variables present in the wood having meaningful differences are: vessel length, number of pores $/ \mathrm{mm}^{2}$; fiber external and internal diameter, fiber wall thickness, as well as ray length. In bark, the principal differences reside in the external aspect. Both species present evolutionary characters in wood and bark.
\end{abstract}

KEY WORDS:

Anatomy, bark, Geoffroea, wood. 


\section{INTRODUCCIÓN}

En la Región Chaqueña Argentina vegetan dos especies del género Geoffroea que son Geoffroea striata Morong (manduvi-rá) y Geoffroea decorticans Burkart (chañar). Ambas tienen valor florístico y aunque sus maderas son usadas localmente en la actualidad carecen de valor comercial.

Geoffroea decorticans Burkart (chañar) es un elemento xerófilo que forma extensas colonias uniformes a partir de raíces gemíferas (Ulibarri et al., 2002). Su madera es utilizada en carpintería y mueblería rural, sus frutos son comestibles, la corteza se emplea como colorante y en medicina popular, al igual que las hojas (Biloni, 1990). En Argentina se distribuye desde Salta hasta Río Negro. Estas formaciones establecen franjas boscosas alrededor de las áreas inundadas, como bosques en galería o en las orillas de esteros y pantanos, siendo menos frecuentes en el Chaco Occidental.

Geoffroea striata Morong (manduvirá) es un árbol higrófilo de amplia distribución en América meridional, desde Ecuador y Perú a Bolivia, Paraguay y norte de Argentina. Crece en bosques higrófilos al este de Formosa y Chaco y nordeste de Santa Fe y noroeste de Corrientes (distrito Chaqueño Oriental). $\mathrm{Su}$ presencia es escasa; los bosques puros se hallan en el centro y centro Oeste. La formación es definida como un "matorral de inundación" y sujeta a inundaciones temporales, siendo las especies frecuentes Geoffroea striata, Prosopis hassleri, Prosopis ruscifolia y Prosopis nigra. Su nombre vulgar es maní de los indios (en el Chaco) o almendrón en Perú. Es un árbol higrófilo de la selva, de porte mediano, follaje caduco, inerme, de copa densa y desarrollada, mesótona, tiene el fuste corto muy característico por la presencia de un tronco anómalo con costillas a lo largo de todo su desarrollo. De cuarta magnitud (de $10 \mathrm{~m}$ a $14 \mathrm{~m}$ de altura y $0,60 \mathrm{~m}$ DAP), con sistema simpódico de ramificaciones y ramas de crecimiento epítono (Giménez y Moglia, 2003). En 1892, Morong (citado por Burkart, 1952) menciona que los indígenas se alimentan de semillas tostadas, de gusto muy agradable, que le dan el nombre común al árbol. Gancedo (1916) cita que las ramas tiernas se utilizan como filamentos para cuerdas resistentes. Freise (1936 citado por Burkart, 1952) indica que las hojas contienen el alcaloide eserina y que produce una resina rojiza (Biloni, 1990). Su madera es muy poco conocida y no ha sido descrita anatómicamente.

Ambas especies son empleadas en diferentes usos y su madera no es cotizada en el mercado.

\section{OBJETIVOS}

Describir anatómicamente el leño o madera y la corteza de Geoffroea striata contribuiryendo a su conocimiento y comparar su anatomía con la de Geoffroea decorticans.

\section{MATERIAL Y MÉTODOS}

La madera estudiada fue colectada del monte natural de la Localidad Isla del Cerrito en Chaco (distrito Chaqueño Oriental) y Los Flores, en Santiago del Estero (distrito Chaqueño Occidental).

Sitios de estudio. La Isla del Cerrito, Provincia de Chaco, se caracteriza por su estructura florística correspondiente a las selvas en galería y representa un punto interesante en cuanto a sus ecosistemas naturales. La singularidad de la isla es la presencia de ecosistemas de bosques muy variados, además de pajonales, manchones de herbáceas de distintas floración y vegetación acuática caracte- 
rística. De ahí la presencia de especies leñosas arbóreas propias de la selva misionera, que a través de la franja húmeda que rodea los ríos y arroyos constituyen las selvas de galería.

Esta selva higrófila de la ribera del Paraná y parte de sus afluentes, constituye una masa densa de vegetación, compleja, distribuida a manera de una franja discontinua, de ancho variable. Sus suelos profundos y en general bien drenados, tienen características mólicas. Se observa exceso de agua durante todo el año, excepto en los meses de diciembre y enero, con pocos milímetros de déficit. La precipitación total anual es de $1555 \mathrm{~mm}$ y la evapotranspiración es de $1087 \mathrm{~mm}$.

La Localidad de Los Flores es una zona ampliamente transformada por el cambio de uso del suelo, presenta una vegetación degradada, constituida principalmente por un bosque bajo de Prosopis nigra, Schinus fasciculata y Cercidium praecox, acompañado por bosquecillos de Geoffroea decorticans. El sitio pertenece al tipo climático semiárido mesotermal, con nulo o pequeño exceso de agua. Las precipitaciones se concentran en diciembre, enero y febrero.

Se seleccionaron al azar cinco individuos de cada especie según lo establecido para descripciones anatómicas por las normas COPANT (1973). El material de estudio fue obtenido de una rodaja de $5 \mathrm{~cm}$ de grueso cortado a 1,3 $\mathrm{m}$ de altura. De cada disco se obtuvo una pieza de 2 $\mathrm{cm} \times 2 \mathrm{~cm}$ para realizar las preparaciones microscópicas de madera y de corteza. Se tiñeron las preparaciones con crisoidina - acridina roja y azul de astra, montándose en bálsamo de Canadá. Para obtener el material macerado se empleó una solución de una parte de ácido acético glaciar y dos partes de peróxido de hidrógeno (Berlyn y Misksche, 1976).
En las descripciones del leño se siguió la terminología de IAWA (IAWA Comittee on Nomenclature, 1989). Las mediciones anatómicas de los caracteres seleccionados se efectuaron siguiendo las recomendaciones de Muñiz y Coradin (1991), con la medición de 25 elementos por variable e individuo. Las preparaciones microscópicas de corteza se efectuaron siguiendo las técnicas tradicionales empleadas en el leño o xilema, pero sin hervir el material. Las descripciones se realizaron siguiendo los criterios de distribución de patrones de tejidos y la terminología propuestas por Roth (1981), Trockenbrodt (1990) y Junikka (1994). Las imágenes del trabajo fueron tomadas con una video cámara. El leño o madera de chañar ya ha sido descrito por Tortorelli (1956) y por Giménez (1993); para los fines del presente trabajo se colectó material y se realizaron todas las mediciones anatómicas según se indica anteriormente. La corteza de chañar está descrita brevemente en Roth y Giménez (1997), por ello se consigan la descripción según ficha técnica.

\section{RESULTADOS}

\section{Madera de Geoffroea striata}

La madera no presenta diferencia entre albura y duramen, es de color blanco amarillento, lisa y sin veta, con peso específico de 0,59. Los anillos de crecimiento se demarcan por la presencia de parénquima terminal de 1 a 3 estratos de células, siendo a nivel macroscópico poco visibles.

El leño se caracteriza por presentar porosidad semicircular (Fig. 1), con vasos sin contenidos. El histograma de tejidos del leño corresponde a un 16,5\% de vasos; $46 \%$ de parénquima axial y radial, $37,5 \%$ de fibras. Los vasos son de orientación radial, solitarios (Fig. 2) en una 
proporción de $57 \%$, múltiples cortos (28 $\%)$, múltiples largos (12\%), geminados y racemiformes $(2,66 \%)$. Los elementos de vasos presentan placas de perforación simple (Fig. 3 y 4). Son elementos cortos, de longitud promedio de $207 \mu \mathrm{m}(160 \mu \mathrm{m}$ - $250 \mu \mathrm{m})$.

Los vasos son pequeños a medianos con un diámetro tangencial medio de $92 \mu \mathrm{m}(60 \mu \mathrm{m}-300 \mu \mathrm{m})$, poco numerosos a numerosos, con un valor medio de 9,45 vasos $/ \mathrm{mm}^{2}$ (5 $\mu \mathrm{m}$ - 17,5 $\mu \mathrm{m})$. El área media neta de vasos por $\mathrm{mm}^{2}$ es 0,171 . Este parámetro presenta un valor de $r^{2}$ de 0,89 con el diámetro de vasos y de 0,23 correlación con la frecuencia de vasos $/ \mathrm{mm}^{2}$.

Las puntuaciones intervasculares son alternas, pocas, coalescentes, con diámetros de $5,25 \mu \mathrm{m}$, las parénquimavasculares miden $5,22 \mu \mathrm{m}$ y las fibrovasculares $2,5 \mu \mathrm{m}$. El índice de vulnerabilidad (diámetro medio de vasos / número de vasos por $\mathrm{mm}^{2}$ ) es 3,85 y el de mesomorfismo (vulnerabilidad / longitud de elementos de vasos) 0,0186, correspondiendo a los valores de una especie mesófila.

El tejido mecánico está constituido por fibras libriformes cortas, de longitud media de $828 \mu \mathrm{m}$. Las fibras son finas, con diámetro externo de un valor medio de $14 \mu \mathrm{m}$, diámetro interno de $10 \mu \mathrm{m}$ y el espesor medio de pared de $2 \mu \mathrm{m}$ (pared delgada). El parénquima axial es abundante, de tipo paratraqueal unilateral 0 abaxial, confluente en bandas de 2 a 6 células de espesor (Fig. 5). Hay parénquina terminal en bandas más angostas de 1 a 2 células. El parénquima está estratificado como el resto de los ele- mentos del leño. Las células están divididas en series de dos, rectangulares a fusiformes de $100 \mathrm{~mm}$ de longitud media. Se observa la presencia de parénquima axial cristalífero (Fig. 6), con septos formando camadas de células cristalíferas (de 6 a 8).

Los radios leñosos son homogéneos de tipo III de Kribs, con células de contacto (Fig. 7), exclusivamente uniseriados (Fig. 8). Los radios muy bajos tienen una longitud media de $156 \mu \mathrm{m}$ (100 $\mu \mathrm{m}-200 \mu \mathrm{m})$, correspondiente al tipo radios de $>1 \mathrm{~mm}$ (radios bajos); el número de radios por milímetro es de 11,82 (muy numerosos), dispuestos en estratificación total.

En la Tabla 1 se expresan los resultados estadísticos de los caracteres anatómicos del leño o madera de $G$. striata. En la Tabla 2 se presentan los datos estadísticos comparativos de las dos especies.

\section{Descripción de la corteza de Geoffroea striata}

La corteza es de tipo fisurada longitudinalmente; color castaño grisáceo y de consistencia fibrosa. La corteza total tiene entre $8 \mathrm{~mm}$ y $26 \mathrm{~mm}$, alcanzando hasta $50 \mathrm{~mm}$ en plantas más maduras. La corteza externa oscila entre $2 \mathrm{~mm}$ y 14 $\mathrm{mm}$ y la interna entre $6 \mathrm{~mm}$ y $12 \mathrm{~mm}$. El aspecto de la corteza en sección transversal se caracteriza por la presencia de depósitos oscuros en el floema y por la acumulación de numerosas peridermis. Un rasgo relevante son los exudados rojizos, muy abundantes. 


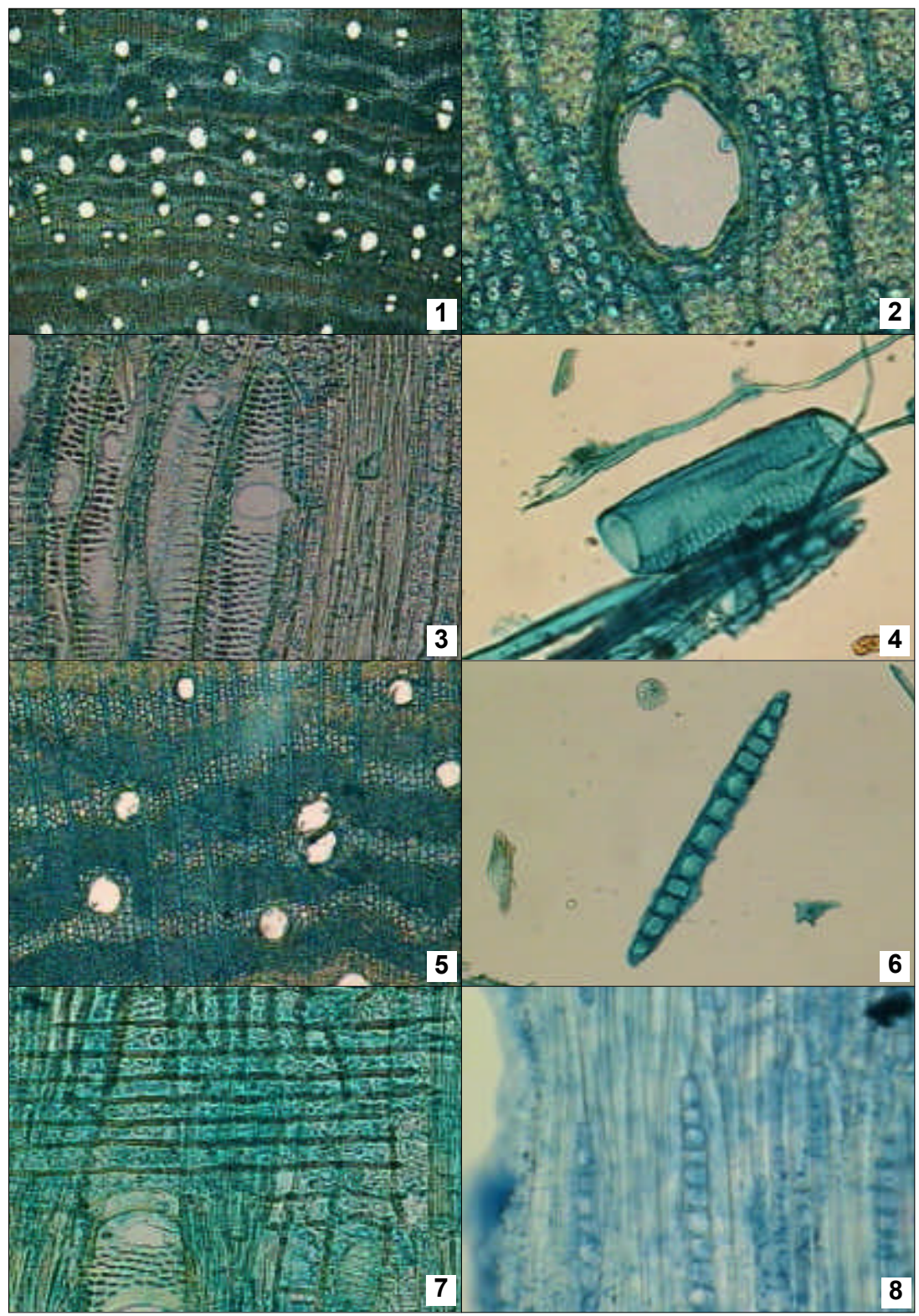

Figuras 1-8. Madera de Geoffroea striata. 1. Leño con porosidad semicircular (x50). 2. Poro solitario rodeado de parénquima paratraqueal $(x 400)$. 3. Sección longitudinal del leño donde se observan vasos con placa de perforación simple (x100). 4. Macerado de tejidos. Miembro de vaso con placa de perforación simple (x100). 5. Parénquima paratraqueal unilateral, confluente en bandas de 2-6 células de espesor (x100). 6. Parénquima axial cristalífero (x100). 7. Radios leñosos homogéneos III Kribs, con células de contacto (x100). 8. Radios uniseriados con estratificación completa $(x 100)$. 
Tabla 1. Caracteres anatómicos del leño o madera de Geoffroea striata

\begin{tabular}{|c|c|c|c|}
\hline CARÁCTER ANATÓMICO & $\begin{array}{l}\text { PROMEDIO } \\
(\mathrm{X})\end{array}$ & $\begin{array}{l}\text { DESVIACIÓN } \\
\text { ESTÁNDAR } \\
\text { (S) }\end{array}$ & $\begin{array}{c}\text { COEFICIENTE } \\
\text { DE VARIACIÓN } \\
(\mathrm{CV} \%)\end{array}$ \\
\hline \multicolumn{4}{|l|}{ VASOS } \\
\hline Tipo de Vasos (\%) & 57 & 8,48 & 14,8 \\
\hline \multicolumn{4}{|l|}{ Solitarios } \\
\hline Múltiples cortos & 28 & 2,82 & 10,1 \\
\hline Múltiples largos & 12 & 5,65 & 47 \\
\hline Geminados y racemiformes & 2,66 & 0,57 & 21,6 \\
\hline Longitud de vasos ( $\mu \mathrm{m})$ & 207,56 & 20,10 & 9,6 \\
\hline Diámetro tangencial de vasos $(\mu \mathrm{m})$ & 92,92 & 38,30 & 41 \\
\hline Número de vasos $/ \mathrm{mm}^{2}$ & 24,08 & 10,51 & 80 \\
\hline Area neta de vasos $\mathrm{mm}^{2}$ & 0,17 & 0,15 & 8,6 \\
\hline \multicolumn{4}{|l|}{ FIBRAS } \\
\hline Longitud $(\mu \mathrm{m})$ & 828,18 & 102,52 & 12 \\
\hline Diámetro externo $(\mu \mathrm{m})$ & 14,60 & 0,83 & 14,21 \\
\hline Diámetro interno $(\mu \mathrm{m})$ & 10,23 & 2,30 & 22,31 \\
\hline Espesor pared $(\mu \mathrm{m})$ & 2,22 & 0,93 & 42,39 \\
\hline \multicolumn{4}{|l|}{ RADIOS } \\
\hline Longitud & 155,61 & 25,40 & 16,3 \\
\hline Número radios/mm & 11,82 & 2,60 & 22 \\
\hline Uniseriados & 100 & & \\
\hline \multicolumn{4}{|l|}{ TEJIDOS \% } \\
\hline Vasos & 16,5 & 0,71 & 4,28 \\
\hline Parénquima radial y axial & 46,0 & 1,41 & 3,1 \\
\hline Fibras & 37,5 & 0,71 & 1,8 \\
\hline
\end{tabular}


Tabla 2. Comparación de caracteres anatómicos del leño o madera de Geoffroea striata y de Geoffroea decorticans

\begin{tabular}{|c|c|c|c|}
\hline CARÁCTER ANATÓMICO & $\begin{array}{c}\text { Geoffroea } \\
\text { striata }\end{array}$ & $\begin{array}{c}\text { Geoffroea } \\
\text { decorticans }\end{array}$ & $\begin{array}{c}\text { PRUEBA DE } \\
\mathrm{t}\end{array}$ \\
\hline \multicolumn{4}{|l|}{ VASOS } \\
\hline Longitud de vasos $(\mu \mathrm{m})$ & 207,56 & 178,56 & *** \\
\hline Diámetro tangencial de vasos $(\mu \mathrm{m})$ & 92,92 & 74,87 & NS \\
\hline Número de vasos/mm2 & 24,08 & 34,18 & *** \\
\hline Area neta de vasos, $\mathrm{mm} 2$ & 0,17 & 0,16 & NS \\
\hline \multicolumn{4}{|l|}{ FIBRAS } \\
\hline Longitud $(\mu \mathrm{m})$ & 828,18 & 819,05 & NS \\
\hline Diámetro externo $(\mu \mathrm{m})$ & 14,60 & 10,56 & $* \star *$ \\
\hline Diámetro interno $(\mu \mathrm{m})$ & 10,23 & 5,45 & *** \\
\hline Espesor pared $(\mu \mathrm{m})$ & 2,216 & 2,55 & *** \\
\hline \multicolumn{4}{|l|}{ RADIOS } \\
\hline Longitud $(\mu \mathrm{m})$ & 155,61 & 101,22 & *** \\
\hline Número radios/mm & 11,82 & 16 & NS \\
\hline \multicolumn{4}{|l|}{ PORCENTAJE DE TEJIDOS (\%) } \\
\hline Vasos & 16,5 & 31 & \\
\hline Parénquima radial y axial & 46,0 & 29 & \\
\hline FIBRAS & 37,5 & 40 & \\
\hline \multicolumn{4}{|l|}{ Tipo de vasos } \\
\hline Solitarios & 57 & 61 & \\
\hline Múltiples cortos & 28 & 26 & \\
\hline Múltiples largos & 12 & 5 & \\
\hline Geminados y racemiformes & 2,66 & 8 & \\
\hline Uniseriados & 100 & 68 & \\
\hline PARÉNQUIMA AXIAL & $\begin{array}{c}\text { Paratraqueal } \\
\text { unilateral, } \\
\text { confluente en } \\
\text { bandas de } 2 \text { a } \\
6 \text { células } \\
\end{array}$ & $\begin{array}{c}\text { Confluente en } \\
\text { bandas } \\
\text { interrumpidas } \\
\text { de } 2 \text { a } 6 \\
\text { células } \\
\end{array}$ & \\
\hline INDICE DE VULNERABILIDAD & 3,85 & 2,19 & \\
\hline INDICE DE MESOMORFISMO & 0,0186 & 0,012 & \\
\hline RADIOS & $\begin{array}{c}\text { Estratificación } \\
\text { total }\end{array}$ & $\begin{array}{c}\text { Estratificación } \\
\text { total }\end{array}$ & \\
\hline
\end{tabular}


Caracterización microscópica. El floema no colapsado está constituido por elementos esclerénquimáticos y no esclerenquimáticos. Presenta fibras floemáticas en bandas tangenciales interrumpidas sólo por los radios uniseriados (Fig. 9). Las fibras se alternan con bandas tangenciales de parénquima axial septado con cristales en cada septo (Fig. 10). El floema no colapsado está dispuesto en estratos. El rasgo anatómico característico del floema es la presencia de un sistema interconectado de células secretoras que se disponen tangencialmente en grupos de más de 20 células (Fig. 11). Son humeriformes, contienen una goma rojiza (Fig. 12). En el floema colapsado se obliteran los tubos cribosos después de 2 bandas de fibras (Fig. 13), iniciándose la dilatación de los radios en forma irregular, por efecto de la dilatación de las células parenquimáticas (Fig. 14). No hay formación de células pétreas.

El ritidoma es de tipo escalar, con peridermis medianamente desarrollada (Fig. 15). El súber está formado por 10 a 20 estratos de células con paredes delgadas (Fig. 16), presenta felógeno poco desarrollado. El ritidoma acumula más de 2 peridermis, en individuos adultos se han contabilizado un número superior a 10.

\section{Descripción de la corteza de Geoffroea decorticans}

La corteza de esta especie es uno de los rasgos morfológicos más notorios para su rápida identificación. Presenta dos aspectos, de acuerdo con la edad del árbol. En individuos jóvenes es de color verdoso amarillenta, dehiscente en tiras ocráceas que dejan ver la corteza nueva (este dato le da el nombre específico); en adultos, se presenta en placas rectangulares de coloración parda y consistencia quebradiza, que determinan un patrón fisurado longitudinalmente. La corteza tiene uso medicinal junto con las hojas como emoliente y antiasmático; hervida se emplea como material colorante café para teñido de telas.

Estructura microscópica. El floema presenta fibras floemáticas (Fig. 17), en bandas tangenciales (Fig. 18) interrumpidas sólo por los radios uniseriados muy frecuentes $(16 / \mathrm{mm})$. Las fibras del floema son pequeñas $(10 \mu \mathrm{m}$ de diámetro externo), de paredes gruesas dispuestas en hileras radiales de 2 a 4 células de espesor. Las fibras están acompañadas en todo su trayecto por cristales dispuestos en parénquima septado; radios con dilatación media.

Largas estructuras secretoras se disponen en bandas tangenciales con contenido rojizo (Fig.19). Estas células secretoras (humeriformes) forman un sistema interconectado de células verticales (Fig. 20). La peridermis se desarrolla en árboles adultos y presenta células de paredes muy delgadas. Las células del súber presentan paredes gruesas, algunas con contenidos pardos. Hay acumulación de 2 o más peridermis. En la tabla 3 se presentan los datos comparativos de la estructura de la corteza de ambas especies

\section{DISCUSIÓN}

Los rasgos característicos tanto del leño como de la corteza en ambas especies son similares. Para diferenciarlas es necesario realizar mediciones para individualizar cada especie a nivel microscópico. Los aspectos más notorios del género son: la estratificación total del leño y la presencia de células secretoras en el floema. 


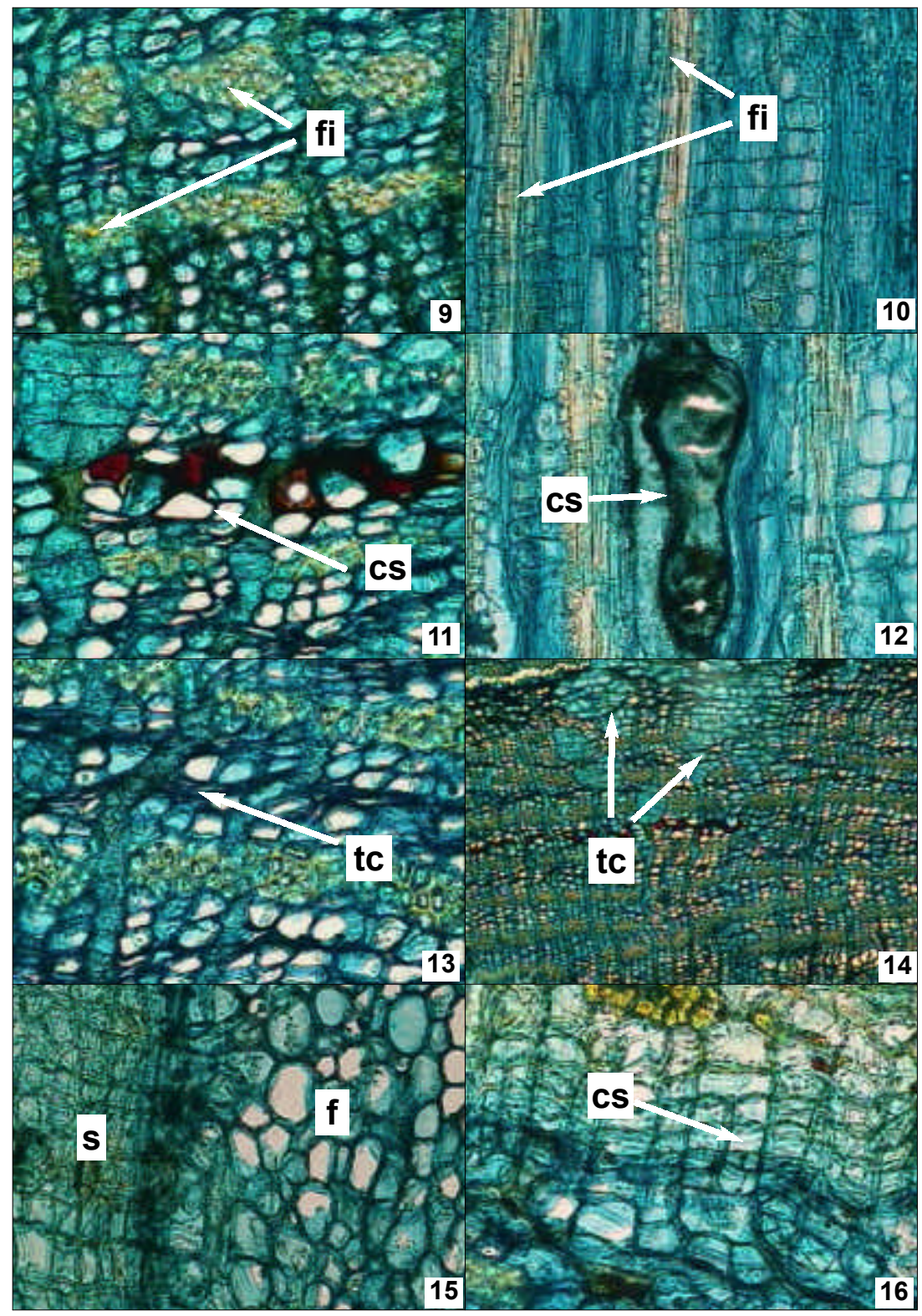

Figuras 9-16. Corteza de Geoffroea striata. 9. Fibras (fi) en el floema en bandas tangenciales (x400). 10. Fibras del floema acompañadas por cristales en camadas de parénquima septado $(x 400)$. 11. Sistema interconectado de células secretoras $(x 400)$. 12. Vista longitudinal de una célula secretora (x1000). 13. Sección transversal del floema colapsado con tubos cribosos obliterados $(x 400)$. 14. Sección transversal del floema donde se manifiesta la dilatación de los radios $(r)(x 100)$. 15. Peridermis: a la derecha se observa la felodermis $(f)$ a la izquierda el súber (s) (x1000). 16. Células suberosas (cs) de paredes delgadas (x1000). 


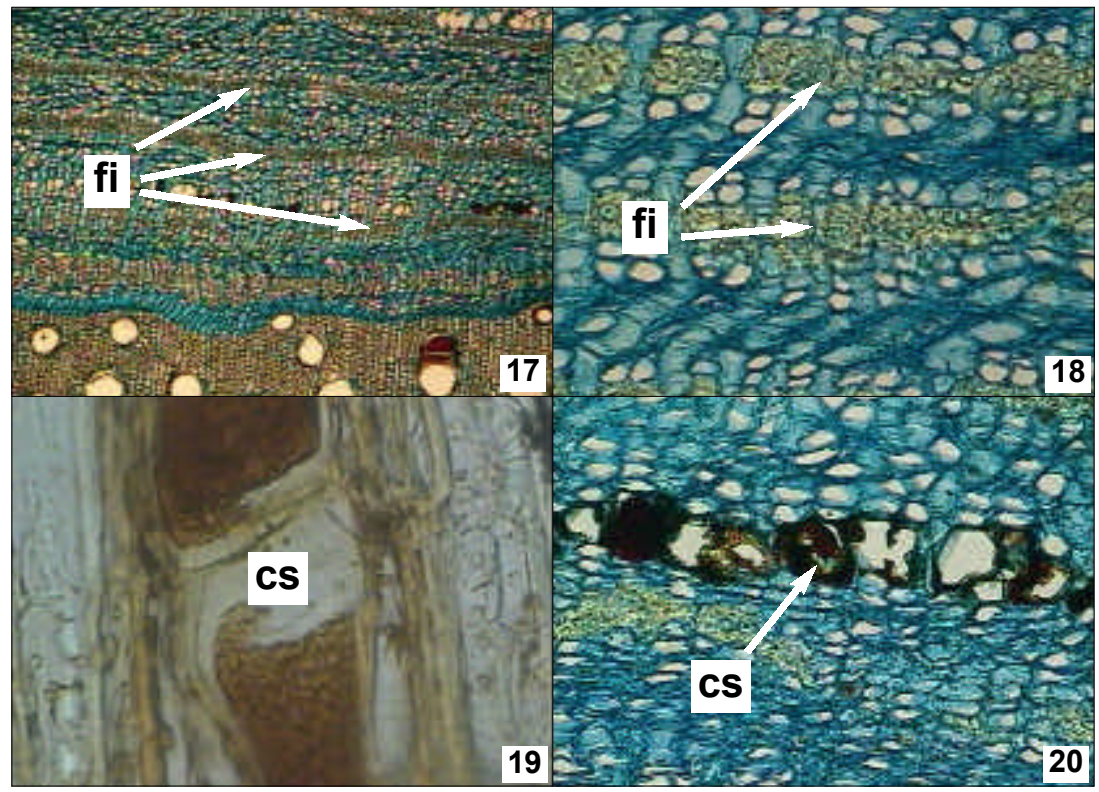

Figuras 17-20. Corteza de Geoffroea decorticans. 17. Sección transversal del floema, donde se evidencia las fibras (fi) en bandas tangenciales (x100). 18. Tejido mecánico en placas superpuestas que originan bandas tangenciales. $(x 400)$. 19. Células secretoras humeriformes $(x 1000)$. 20. Células secretoras dispuestas en bandas tangenciales $(x 400)$.

Tabla 3. Rasgos comparativos de las cortezas

\begin{tabular}{lll}
\hline CARACTERES & Geoffroea striata & Geoffroea decorticans \\
\hline Tipo de corteza & Fisurada longitudinalmente & Fisurada longitudinalmente \\
\hline Estructuras de secreción & $\begin{array}{l}\text { Sistema de células verticales } \\
\text { dispuestas en bandas } \\
\text { tangenciales }\end{array}$ & $\begin{array}{l}\text { Sistema de células } \\
\text { verticales dispuestas en } \\
\text { bandas tangenciales }\end{array}$ \\
\hline Fibras floemáticas & $\begin{array}{l}\text { En bandas tangenciales } \\
\text { interrumpidas sólo por los } \\
\text { radios uniseriados }\end{array}$ & $\begin{array}{l}\text { En bandas tangenciales } \\
\text { interrumpidas sólo por los } \\
\text { radios uniseriados muy } \\
\text { frecuentes (16/mm). }\end{array}$ \\
\hline Dilatación de radios & $\begin{array}{l}\text { En forma media e irregular, } \\
\text { produciéndose la dilatación } \\
\text { de las células } \\
\text { parenquimáticas }\end{array}$ & Escasa \\
\hline Súber & De paredes delgadas & $\begin{array}{l}\text { De pared desigualmente } \\
\text { engrosadas }\end{array}$ \\
\hline Acumulación de ritidoma & De 2 o más & De 2 o más \\
\hline
\end{tabular}


La familia Fabaceae que es ampliamente distribuida, presenta una gran heterogeneidad desde el punto de vista anatómico debido precisamente a su amplísima diversidad de hábitat.

Los vasos múltiples radiales de 2 a 3 , la porosidad circular o semicircular en el $25 \%$ de los géneros, la presencia de placas de perforación simple, los elementos de vaso cortos a muy cortos son características de la madera o del leño de este género.

La frecuencia de vasos $/ \mathrm{mm}^{2}$ es un indicativo muy importante relacionado con el tipo de clima de una región. Un número elevado de vasos es frecuente encontrarlo en especies de ambientes secos (Carlquist y Hoeckman, 1985) o fríos (Miller, 1975), constituyendo una expresión muy sensible del xerofitismo o mesomorfismo, por lo que se considera una de las variables para determinar el índice de mesomorfismo. Geoffroea decorticans (cuya estrategia ante el déficit hídrico es producir vasos con diámetros más pequeños y con mayor número de vasos) presenta rasgos de menor vulnerabilidad que Geoffroea striata.

En las fabaceas, el parénquima es abundante, en bandas, aliforme o vasicéntrico, con cristales en hileras de células septadas del parénquima paratraqueal. Predominan los radios de 1 a 12 series siendo los más frecuentes aquellos entre 2 y 3 o exclusivamente uniseriados o cerca de serlo (Carlquist, 1988 de la lista modificada de Record, 1944), homogéneos en el $45 \%$ de los géneros, con radios estratificados en los géneros de radios bajos, presentan fibras con puntuaciones simples pequeñas, raramente septadas, de longitud media a cortas.

Los radios exclusivamente uniseriados (menos biseriados) es otro rasgo mencionado para otros géneros como
Dalbergia y Havardia, (Record, 1944, modificada).

Las especies estudiadas presentan estratificación de los elementos constitutivos del leño o madera como carácter muy notorio en la madera. La estratificación completa de radios es citada en varias géneros de Fabaceae como en: Dalbergia, Amburana, Robinia, Sophora, Cassia, Enterolobium, Machaerium, Holocalyx, Myrocarpus, Pterogyne, Ramorinoa, Tamarindus y Tipuana, entre otras (Carquist 1988; Cozzo y Cristiani 1950). La presencia de porosidad circular o semicircular es citada por Carlquist (1988) para algunos géneros de la familia.

El parénquima paratraqueal unilateral es un rasgo anatómico que se presenta en algunas familias con rasgos primitivos tales como en Buxaceae, Clusiaceae, Lauraceae; no obstante, aparece en grupos más evolucionados como en 3 géneros de Fabaceae, Apocinaceae y Combretaceae (Hess, 1946). El parénquima conteniendo cristales está presente en Geoffroea según lo descrito por Carlquist (1988) en Fabaceae, Sapindaceae, Anacardiaceae y Meliaceae. La madera o leño de Geoffroea presenta todos los rasgos anatómicos característicos de esta familia.

Como se observa en la tabla 2 las variables del leño o madera que permiten la diferenciación entre las dos especies son: longitud de vasos, número de vasos $/ \mathrm{mm}^{2}$; diámetro externo, interno y espesor de pared de fibras, así como la longitud de radios, además de los radios exclusivamente uniseriados presentes sólo en G. striata.

Con referencia al hábitat de $G$. striata, ésta es una especie mesófila (índice de vulnerabilidad mayor) y Geoffrea decorticans es menos vulne- 
rable siendo su estructura leñosa de xerófita a mesófita. Con base en los caracteres anatómicos analizados, la madera de G. striata puede ser empleada para usos similares que los de la madera de $G$. decorticans como madera aserrada para carpintería y mueblería, cabos de herramientas y para leña.

Con relación a la corteza, ambas especies presentan caracteres similares, que responden a los descritos para la familia Fabaceae, citados por Roth (1981) y se resumen en: 1) tejido esclerenquimático del floema en forma de fibras; 2) distribución de las fibras floemáticas de manera heterogénea que van desde grupos irregulares pequeños a grandes, placas alternantes, placas superpuestas, bandas transversales, hasta bandas que forman anillos estratificados.

Para los géneros Lonchocarpus, Machaerium, Pterocarpus (Roth, 1981), Erythrina, y Geoffroea (Roth y Giménez, 1997) se menciona que presentan corteza con placas superpuestas que originan bandas tangenciales. La regularidad en la distribución del tejido duro como se manifiesta en Geoffroea es considerada como un rasgo de evolución avanzada.

El sistema secretor es distintivo en Fabaceae, son células secretoras interconectadas que presentan un patrón de distribución de tejidos floemáticos muy característico. La presencia de bandas tangenciales de células interconectadas son descritas como presentes en Machaerium, Centrolobium (Roth, 1981) y Geoffroea (Roth y Giménez, 1997).

La presencia de cristales de oxalato de calcio es característica en el floema de Fabaceae, especialmente solitarios en parénquima septado de paredes delgadas. Están presentes en todos los géneros acompañando a los haces de fibras floemáticas.
El ancho de los radios liberianos presenta una variabilidad muy alta en esta familia. En los géneros Pterocarpus, Dipteryx, Centrolobium (Roth, 1981) y Tipuana (Tortorelli, 1956) se presentan radios exclusivamente uniseriados (excepcionalmente biseriados). Geoffroea striata presenta radios exclusivamente uniseriados pero no así Geoffroea decorticans (radios con una o dos series). El ritidoma es escalar, con acumulación de varias peridermis.

La corteza de Geoffroea reúne un conjunto de caracteres que indican la presencia de un género evolucionado, con un tejido mecánico dispuesto en forma de placas regulares (bandas) que determinan la estratificación de tejidos del floema; radios estratificados; parénquima confluente abundante, dilatación de radios y ritidoma desarrollado.

\section{CONCLUSIONES}

Geoffroea striata es una especie de gran afinidad anatómica con Geoffroea decorticans, pudiendo tener un uso alternativo de su madera.

Las variables anatómicas del leño que permiten su diferenciación son: longitud de vasos, número de vasos $/ \mathrm{mm}^{2}$; diámetro externo, interno y espesor de pared de fibras, así como la longitud de radios. En la corteza, las principales diferencias residen en el aspecto externo.

\section{REFERENCIAS}

Berlyn, G. y J. Misksche. 1976. Botanical microtechnique and cytochemistry. lowa State University, Ames, IOWA.

Biloni, S.J. 1990. Árboles Autóctonos Argentinos. Tipográfica Editora Argentina. S.A. 333 p. 
Burkart, A. 1952. Las leguminosas argentinas silvestres y cultivadas. Segunda Edición. Editorial ACME S.A.. Buenos Aires. 569 p.

Carlquist, S. 1988. Comparative wood anatomy. Systematic, Ecological and Evolutionary Aspects of Dicotyledon Woods. Springer, Berlin, Heidelberg, Nueva York. 460 p.

Carlquist, S y D. Hoeckman. 1985. Ecological wood anatomy of the woody Southern California flora. IAWA Bull. N S (6):319-347.

COPANT. 1973. Comisión Panamericana de Normas técnicas. (30):1-19.

Cozzo, D. y L. Cristiani. 1950. Los géneros de Fanerógamas argentinas con estructura leñosa estratificada. Rev Inst Nac Invest Cienc Nat Bot (1):1-6.

Gancedo, A. 1916. Flora Arbórea del Territorio Nacional del Chaco y Proyecto de Ley. Buenos Aires.

Giménez, A.1993. Rasgos estructurales característicos del leño secundario de las especies arbóreas de la región chaqueña seca. Rev. Quebracho (1):1-14.

Giménez, A. y J. Moglia. 2003. Árboles del Chaco Argentino- Guía para el reconocimiento dendrológico. Ministerio de Desarrollo Social de la Nación y Facultad de Ciencias Forestales- Universidad Nacional Santiago del Estero. Editorial El Liberal. 370 p.

Hess, R. 1946. Keys of American Woods XX. Woods with unilaterally paratracheal parenchyma. Trop woods (85): 1-19.
IAWA Committee on Nomenclature. 1989. IAWA List of microscopy features for Hardwood Identification. 322 p.

Junikka, L. 1994. Survey of English macroscopic bark terminology. IAWA J. Vol 15(1) 3-46.

Miller, H. 1975. Anatomical characteristics of some woody plants of the Angmassalik district of Southeast Greenland. Medd. Groenl. 198(6): 1- 30.

Muñiz, G. y V. Coradin. 1991. Norma de procedimientos en estudios de anatomía da madeira. II Gimnospermae Comissae de estudios. CE: 11.01.07.002. ABNT. Brasilia: Laboratorio de Produtos Florestais, Serie Técnica. 117 p.

Record, S. 1944. Keys to American woods. XIV. Dicotyledonous woods with xylem rays virtually all uniseriate. Trop Wood (79): 15- 34.

Roth, I. 1981. Structural patterns of tropical barks. Encyclopedy of Plant Anatomy. 609 p.

Roth, I. y A. Giménez B. 1997. Argentine Chaco Forests. Dendrology, tree structure, and economic use. 1-The Semid-arid Chaco. Encyclopedia of Plant Anatomy. Gerbruder Borntraeger. Berlin Stuttgart. 180 p.

Tortorelli, L. 1956. Maderas y bosques argentinos. Editorial ACME, SA. Cl. Buenos Aires. 891 p.

Trockenbrodt, M. 1990. Survey and discussion of the terminology used in bark anatomy. IAWA Bull. n.s.11: 141-166. 
Ulibarri, E.; E. Gómez Sosa; A. Cialdella;

R. Fortunato y D. Bazzano. 2002.

Leguminosas nativas y exóticas.

Biota Rioplatense VII. Editorial

L.O.L.A. 320 p. $\diamond$

Manuscrito recibido el 30 de septiembre de 2003.

Aceptado el 4 de marzo de 2004.

Este documento se debe citar como:

Giménez, A.M. 2004. Anatomía comparada de leño y corteza de Geoffroea striata y Geoffroea decorticans. Madera y Bosques 10(1):55-68. 